\title{
The Carotid Siphon: A Scanning Electron Microscope Assessment of its Embolic Potential
}

\author{
F.W. Saunders, P. Shedden
}

\begin{abstract}
The role of the carotid siphon as a source of embolic material has had limited morphological or clinical study. The morphologic data available suggests that the siphon plays only a small role in embolic cerebrovascular disease. Clinical studies, however, suggest that it has a significant ischemic potential. To clarify this apparent discrepancy, we have designed a scanning electron microscope study of the carotid siphon. Eighty percent of the specimens from the carotid bifurcation and $30 \%$ of the siphon specimens showed evidence of damaged endothelium with attached red cell and platelet debris. The embolic potential of the siphon is estimated to be between $1 / 3$ to $1 / 2$ that of the carotid bifurcation. This supports the most recent clinical studies.
\end{abstract}

RÉSUMÉ: Le siphon carotidien: détermination de son potientiel embolique grace au microscope électronique à balayage Il existe peu d'études morphologiques ou cliniques sur le rôle du siphon carotidien comme source de matériel embolique. Les données morphologiques disponibles suggèrent un rôle plutôt effacé au siphon dans la maladie cérébrovasculaire embolique. Par contre les études cliniques suggèrent un potential ischémique important. Nous présentons une étude au microscope électronique à balayage afin de clarifier cette dichotomie. $80 \%$ des échantillons de la bifurcation carotidienne et $30 \%$ de ceux du siphon montrent des évidences d'endothélium endommagé avec globules rouges attachés et débris plaquettaires. Le potentiel embolique du siphon est évalué à $1 / 3$ ou $1 / 2$ celui de la bifurcation carotidienne, en accord avec les études cliniques récentes.

Can. J. Neurol. Sci. 1985: $12: 263.266$

The Joint Study of Extracranial Arterial Occlusion, as reported by Blaisdell et al.(1968), revealed that carotid siphon disease is a common entity. The development of EC-IC procedures as a method of circumventing carotid siphon pathology has stimulated a renewed interest in the natural history of this area. Moossy (1966) and Fisher (1965) have published gross and microscopic studies of siphon atheroma claiming that although a large degree of stenosis may exist, the intima, in the majority of cases, appears to be intact and free of potential embolic material. Clinical studies by Craig et al.(1982) and Marzewski et al. (1982), however, suggest that significant ischemic potential exists with siphon atheroma. We have attempted to reconcile this apparent discrepancy by studying arteriosclerotic carotid siphons with the scanning electron microscope (SEM). Attention was paid to the presence or absence of intact endothelium, red cells and platelets that are thought to represent the pathologic corrolate of embolic cerebrovascular disease. Our findings were compared to the published SEM studies of carotid bifurcations to substantiate our methods and findings.

\section{METHODS}

Twenty patients, over 50 years of age, with a history of cerebrovascular symptoms had their extracranial and intracranial vessels removed at the time of autopsy. Each patient had a history of having suffered a transient ischemic attack (TIA) or stroke. The vascular territory of involvement, however, was not always obtainable from the recorded history. Sections from each siphon and bifurcation were taken for examination. This resulted in 4 specimens from each patient and a total of 80 examinations. Initially, each specimen was prepared by two techniques: one set was fixed in a modified Karnovsky's Solution of $2 \%$ glutaraldehyde plus $2 \%$ paraformaldehyde in $0.2 \mathrm{M}$ cacodylate buffer at $\mathrm{pH} 7.4$ and a second set was fixed in $10 \%$ formalin.

After fixation, by either method, the specimens were dehydrated in a graded ethanol series and left in $100 \%$ ethanol for 48 hours to ensure complete formalin removal. Freon 113 was the exchange fluid used in the transfer of specimens to the Polaron Critical Point Dryer. The critical point drying process involved 
4 initial $\mathrm{CO} 2$ flushes, then a 1 hour wait in $\mathrm{CO} 2$ liquid followed by 4 subsequent $\mathrm{CO} 2$ flushes and ending with the warm up phase.

The specimens were mounted on aluminum EM stubs using a mixture of carbon powder and cyanoacrylate adhesive. The samples were then gold-palladium plated for 3 minutes (2.2-2.4 kv, 15 mAmps) using a Polaron E5 Spulter Coater. Each specimen was reviewed on a Hitachi S 4500 SEM at an operating voltage of $25 \mathrm{kv}$. Photographs were taken using type 552 Polaroid Film.

We found that either method of initial specimen fixation was acceptable. The fine detail was better with the modified Karnovsky's Solution but the significant findings were easily visible with either technique. Each method gave results comparable to published SEM photographs of carotid bifurcations by Hertzer et al.(1977) and Dujovny et al.(1981). The final half of our specimens were fixed in $10 \%$ formalin only.

\section{RESULTS:}

Carotid Bifurcations All specimens showed evidence of atheroma formation on gross, microscope and SEM examination. The amount of stenosis and ulceration however, varied widely. Twenty percent of specimens showed intact endothelium over areas of atheroma. The surfaces were clear of red cell or platelet debris. Eightly percent, however, showed what is thought to be the pathological counterpart of embolic cerebrovascular disease. Some of these specimens showed what seemed to be a continuum of disease that began with the humping up of atheromatous debris under intact intima. (Fig.1) These mounds eventually erode through the endothelium exposing plaque and collagen to the circulating blood components. Red cells, platelets and fibrin deposit on these exposed surfaces creating fronds of loosely held debris. (Fig.2) Other specimens revealed crater formation without significant stenosis. The craters consisted of denuded endothelium with attached circulating blood elements. (Fig.3) The nonstenotic crater formation was a less common finding in the bifurcation specimens. Because some vessels showed both the "fronds" pattern and "crater" pattern, however, absolute numbers and percentages of their frequency of occurrence would be misleading.

Carotid Siphons All siphons showed arteriosclerotic involvement. The average degree of stenosis was between $30 \%-50 \%$. Contrary to what was seen in the bifurcation specimens, $70 \%$ of siphon specimens had an intact endothelium over a variable degree of subintimal plaque. (Fig.4) The remainder, about 30\%, showed the same range of pathologic findings that was seen in the carotid bifurcation. Both the protruding mounds of atheromatous debris and the nonstenotic ulceration associated with red cell and platelet debris were identified. (Fig.5,6) Despite the fact that the endothelial layer was broken and blood elements were seen attached to the surface, the siphon lesions did not produce the fronds of potentially embolic material protruding into the lumen that were frequently seen at the bifurcation.

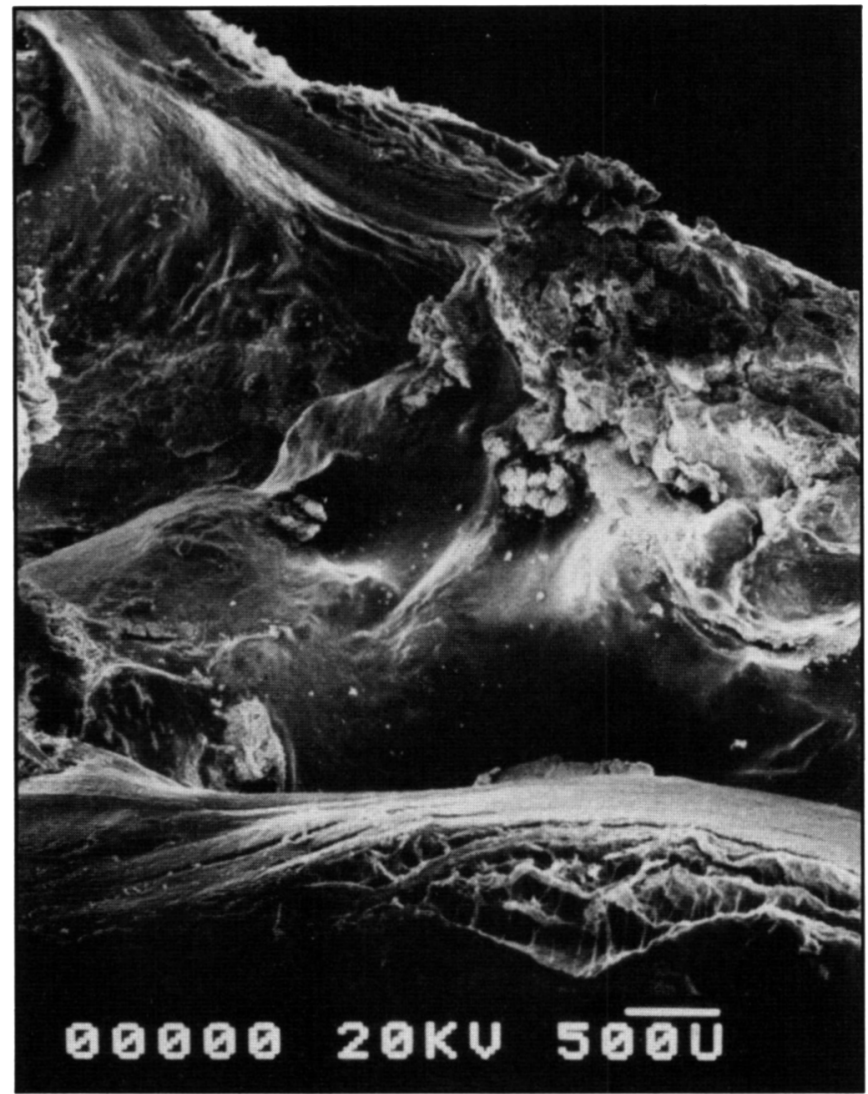

Figure $2-$ Bifurcation specimen:Protruding fronds of atheroma with attached blood elements.
Figure I - Bifurcation specimen:Thick atheromabeginning tobreakthrough intimal cover. Calibration bar and number of microns represented is shown at lower right in this and subsequent illustrations.

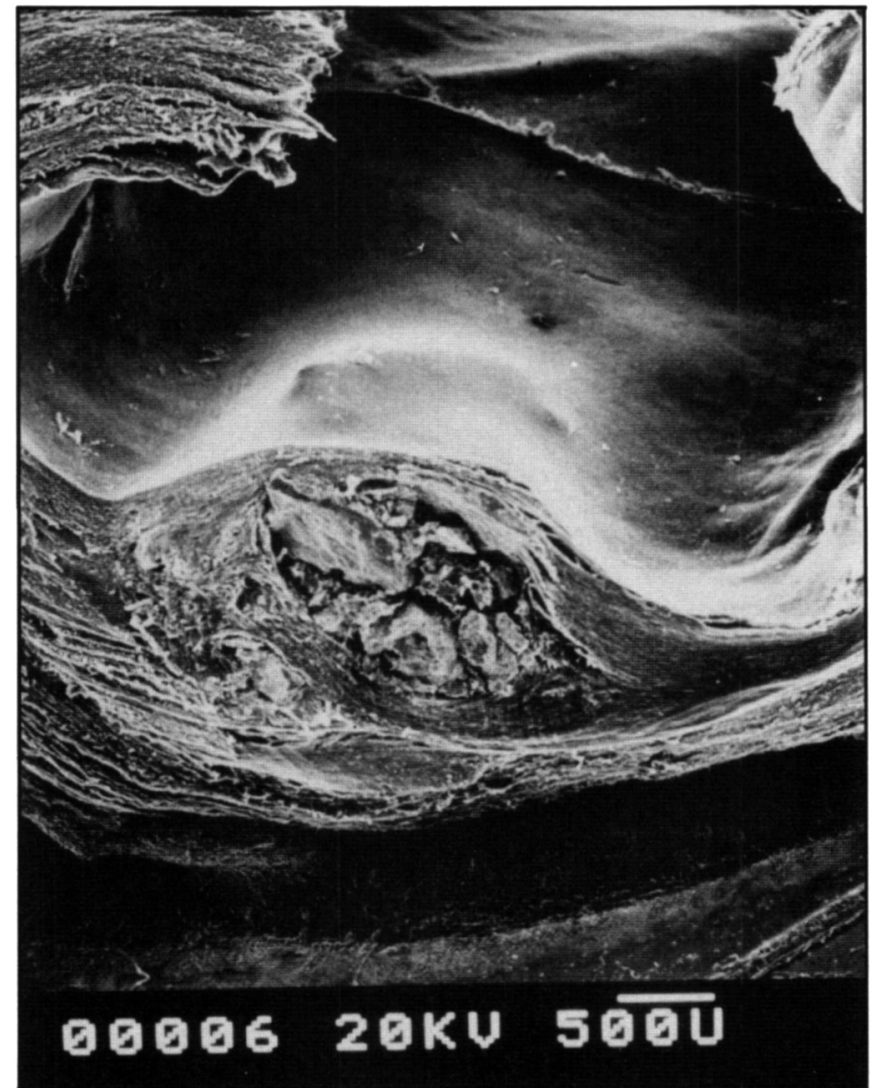




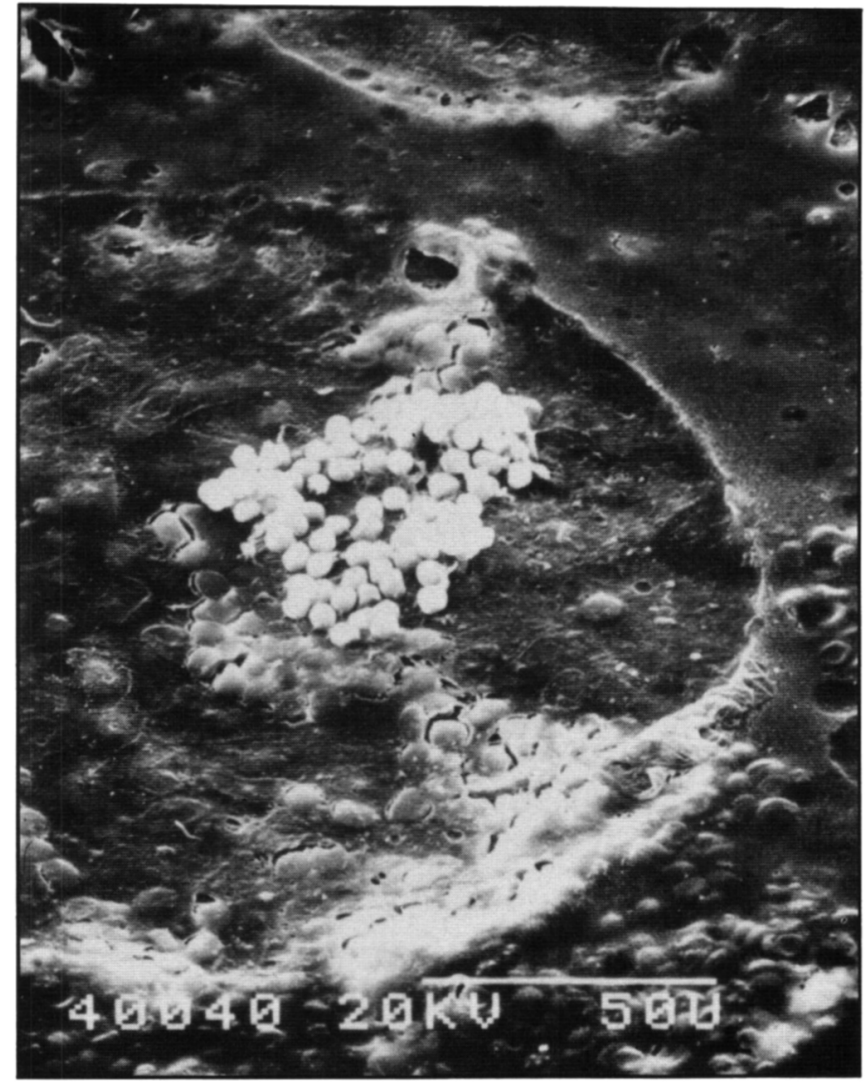

Figure 3 - Bifurcation specimen: Nonstenoic ulceration with anached red cells.

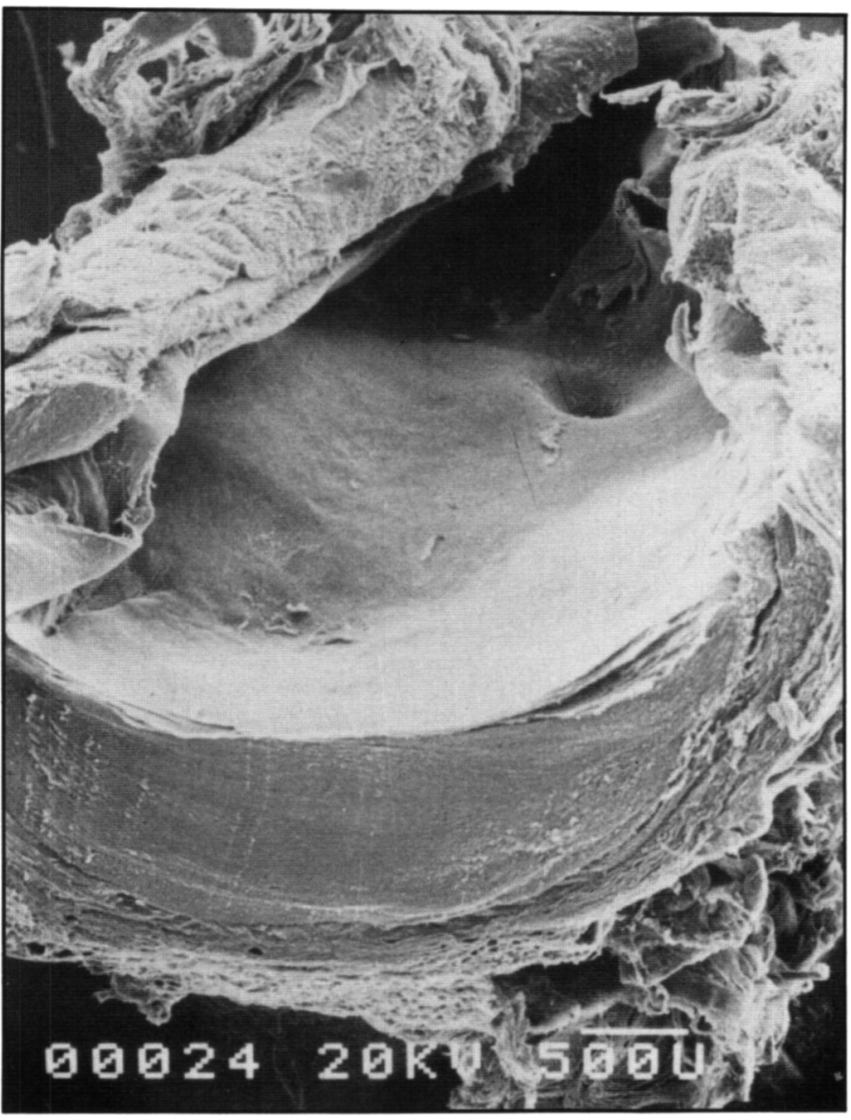

Figure 4 - Siphon specimen: Thick atheroma covered by intact intima.

\section{Discussion}

We can deduce from the literature the frequency of carotid siphon disease. Blaisdell et al.(1968) estimated that $6 \%$ of cerebrovascular patients had purely inaccessible disease; another $33 \%$ had disease at both accessible and inaccessible areas or "tandem disease". Adding these two figures together gives us approximately $35 \%-40 \%$ of cerebrovascular patients that have inaccessible disease requiring assessment. Inaccessible disease is comprised of two main components: siphon disease and middle cerebral disease. Hass et al.(1968) reporting statistics from the Joint Study, recorded an incidence of $13.3 \%$ and $11.9 \%$ respectively. An initial report by Barnett (1981) on patients submitted for the EC-IC trial showed that $17 \%$ had siphon disease whereas $10 \%$ had middle cerebral stenosis and $12 \%$ had middle cerebral occlusion. It appears that siphon disease represents about $50 \%$ of inaccessible disease and would therefore be found in approximately $18 \%-20 \%$ of cerebrovascular patients.

Pathological studies of the carotid siphon are sparse. Moossy (1966) concluded from his study of cerebral atherosclerosis that "ulceration is uncommon in cerebral arterial plaques". Fisher (1965) looked specifically at the carotid siphon and commented that "with heavily calcified siphons the inner surface of the artery was corrugated showing bony-hard yellowish-brown excresences, pits, and shiny smooth areas that formed an irregular, porous-appearing labyrinth through which it was sometimes difficult to trace the lumen of the vessel. The intima was not ulcerated". These studies seemed to indicate that sources of embolic debris were unusual and that siphons, except for their stenotic potential, did not pose a frequent source of embolic cerebrovascular disease.

Clinical studies are also limited in number. Cole and Davis (1963), in a retrospective study, found a higher incidence of cerebrovascular disease in patients with calcified carotid siphons than in matched controls. This is difficult to interpret because it implies that calcification is related to atherosclerosis and that it is the siphon disease that caused the higher incidence of cerebrovascular events; neither assumption may be true. Roeder et al.(1983) recorded the degree of siphon stenosis at the time of carotid endarterectomy. He concluded that the subsequent rate of ischemic deficits bore no relationship to the presence or absence of siphon disease.

Craig et al.(1982) retrospectively reviewed 58 patients with siphon disease that had at least $30 \%$ stenosis. These patients had a $19 \%$ ipsilateral stroke rate and a stroke rate per year of 7.5\%. Marzewski et al. (1982) reviewed that Cleveland Clinic experience with patients whose siphon disease exhibited greater than $50 \%$ stenosis. They found an $18 \%$ ipsilateral stroke rate with an incidence of 5\% per year. Both papers concluded that siphon disease was associated with a significant stroke risk and must be considered when treating cerebrovascular patients.

The results from our SEM study of the carotid siphon bridge the apparent gap between the gross and microscopic studies and the clinical evidence at hand. We found that, similar to the carotid bifurcation situation, SEM studies revealed areas of ulceration and deposits of red cell and platelet debris that were not visible grossly or with light microscopy. Approximately $30 \%$ of these siphons were found to harbour potential sources of embolic material. This supports the findings of the recent clinical studies. 


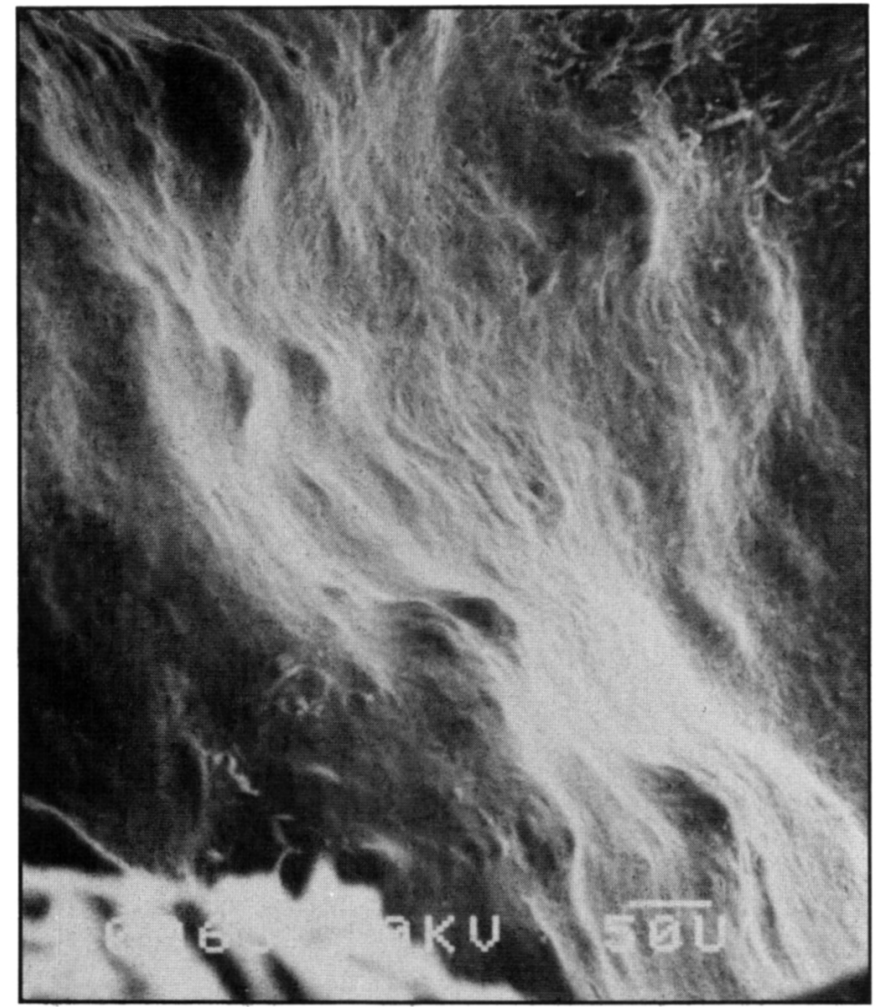

Figure 5 - Siphon specimen: Atheromatous mounds protruding into vascular Iumen.

The incidence of tandem disease in cerebrovascular patients is stated to be $33 \%$. This is not unexpected because atherosclerosis is a generalized disease process. When faced with such a situation it is important to be able to assess the risks between the various points of involvement in the cerebrovascular tree. Following a transient ischemic attack from the carotid bifurcation, $33 \%$ go on to have a stroke, $33 \%$ continue to have TIAs and in $33 \%$, the ischemic spells disappear. This translates into a 33\% stroke risk and an incidence of $10 \%$ per year. It appears from the clinical data of Craig et al.(1982) and Marzewski et al.(1982) that siphon disease, with its ipsilateral stroke rate of $18 \%$ and a $5 \%$ yearly risk, represent approximately $1 / 2$ the risk that emanates from the carotid bifurcation. Morphologic studies support the same conclusion. Hertner et al.(1977) revealed that $80 \%$ of bifurcations had ultrastructural abnormalities that could represent future embolic material. Our assessment of the bifurcation was in agreement with this. In the siphon, however, similar changes were observed in only $30 \%$ of specimens. The ratio of $1 / 3$ to $1 / 2$ is retained and supported.

\section{CONCLUSION}

Siphon disease is encountered in $18 \%-20 \%$ of patients with cerebrovascular disease. Both pathological and clinical studies estimate that the embolic potential of the siphon is between $1 / 3$ to $1 / 2$ that of the carotid bifurcation. It has been the practice of physicians treating tandem disease to treat the extracranial vasculature first and, if symptoms persist, to look at the intracranial component. It appears that there is some rational basis for this approach. Those patients with only siphon disease have had their natural history better defined, both morphologically and clinically, and their treatment awaits the findings of the EC-IC trial.

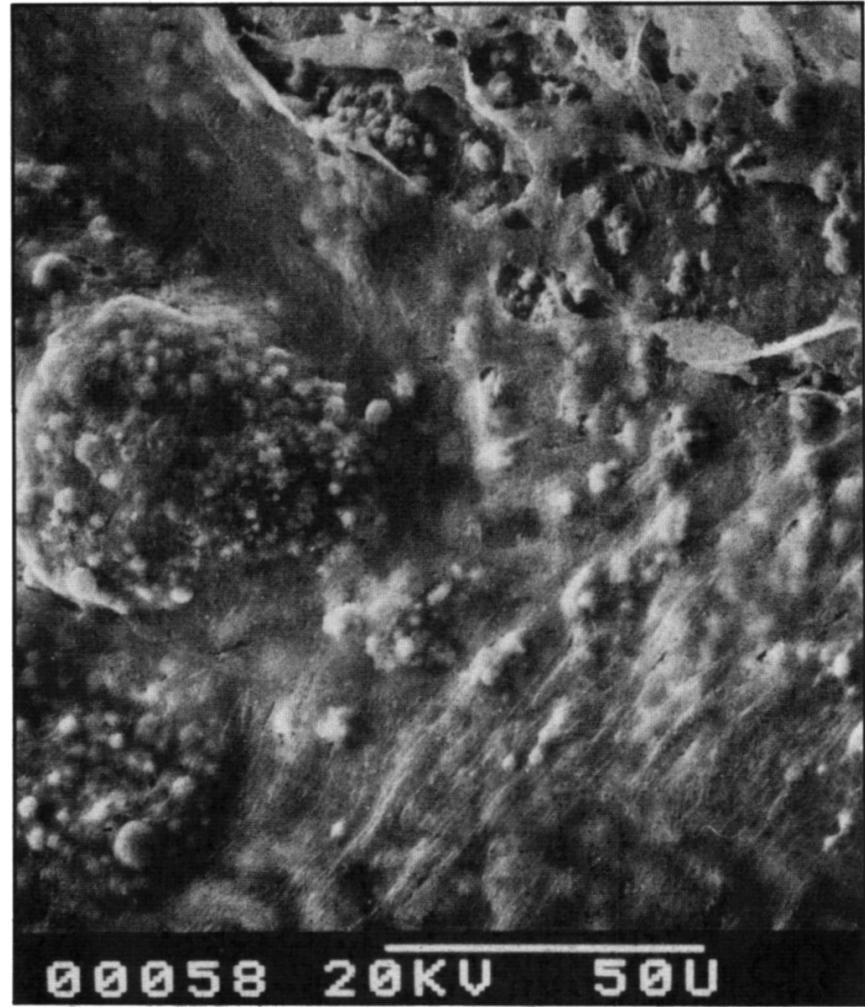

Figure 6 - Siphon specimen: Nonstenoic ulceration of intimal surface.

\section{ACKNOWLEDGEMENTS}

Our thanks for technical expertise and use of laboratory equipment to the Department of Anatomy, Queen's University. Special thanks to Dr. M.G. Joneja and Mrs. J. Lindsay.

\section{REFERENCES}

Barnett HJM, Peerless SJ (1981) Collaoraive EC/IC Bypass Study: The rational and a progress report. In Cerebrovascular Diseases, Moossy $\mathrm{J}$ and Reinmuth OM (Editors), Raven Press, New York, 271-288.

Blaisdell WF, Clauss RH, Galbraith JG et al.(1969) Joint study on extracranial arterial occlusion, IV, A review of surgical considerations. JAMA 12: 209.

Cole M, Davis H (1963) Carotid siphon calcification. Brit J. Radiol. 36:289.

Craig DR, Meguro K, Watridge C, Robertson JT, Barnett HJM, Fox AJ (1982) Intracranial internal carotid artery stenosis. Stroke 13: 825-828.

Dujovny MD, Kossovsky N, Loubeau JM, Nelson D, McManus G (1981) Scanning electron microscopic and x-ray energy spectrographic analysis of the inner surface of human atherosclerotic carotid plaques. Neurosurgery 8: 60-67.

Fisher CM, Gore I, Okabe N, White PD (1965) Calcification of the carotid siphon. Circulation 32: 538-548.

Hass WK, Fields WS, North RR et al.(1968) Joint study of extracranial arterial occlusion. II. Arteriography, techniques, sites and complications. JAMA 203: 159-166.

Hertzer NR, Beven EG, Benjamin SP (1977) Ultramicroscopic ulcerations and thrombi of the carotid bifurcation. Arch. Surg. 112: 1394-1402.

Marzewski DJ, Furlan AJ, St. Louis P, Little JR, Modic MT, Williams $G$ (1982) Intracranial internal carotid artery stenosis: Longterm prognosis. Stroke 13: 821-824.

Moossy, John (1966) Morphology, sites and epidemiology of cerebral atherosclerosis. In Cerebrovascular Disease. Ass. Res. Nerv. Ment. Dis. 41:1

Roedeer GO, Langlois YE, Chan ARW, Chikos PM, Thiele BL, Strandness DE. (1983) Is siphon disease important in predicting outcome of carotid endarterectomy? Arch. Surg 118: 1177-1181. 